\title{
Resolving fractured debates about fracking? The shale gas industry in South Africa
}

Lancashire, England:

Preston New Road Action Group, a local antifracking group, said it was 'devastated' by the decision [to go ahead with fracking]. 'This is a sad day as it is clear to all that this [UK] government neither listens, nor can it be trusted, to do the right thing for local communities. It is deplorable that a [fracking] industry that has been rejected on every level has inflicted itself on Preston New Road,' said Pat Davies, the group's chair. ${ }^{1}$

Eastern Cape, South Africa:

Chief Khomotsoana Lebenya has made a solemn vow to his more than 20000 subjects: fracking will not happen on his land. 'Fracking will not happen here. It will not happen, I promise you. We will chase them. ${ }^{2}$

The extraction of shale gas is often said to have considerable benefits as an alternative and relatively new source of energy and as a creator of jobs, with the consequent social and economic advantages that follow. Why, then, would communities as different and geographically far apart as those in Lancashire and the Eastern Cape be so determinedly opposed to fracking? The reasons are numerous: the extraction process is water intensive in the face of water scarcity; the potentially carcinogenic chemicals used in the process may escape and contaminate ground water; air pollution is also common; heavy transport (for equipment and water) will have substantial environmental impacts; and the activity can ruin valuable or tourist-intensive landscapes. In short, the extraction of shale gas may well present significant environmental, technical, social and economic challenges - along with any benefits that it might bring.

It is for these reasons that the Department of Science and Technology (DST) approached the Academy of Science of South Africa (ASSAf) to undertake an assessment of South Africa's technical readiness to support hydraulic fracturing. ASSAf responded by using the well-tested and effective approach of establishing a consensus study in which a panel of experts undertook the various tasks needed to help to answer the core question. ASSAf launched the resulting consensus report ${ }^{3}$ on 12 October - which has resulted in a substantial number of media reports on the panel's findings and recommendations.

Not surprisingly, the report is extraordinarily comprehensive and covers, in detail, a wide range of background material. This material includes international perspectives, factors to be considered in the case of the Karoo (not forgetting possible impacts on astronomy), a detailed analysis and the presentation of factors and the elements of readiness to be considered in the production phase, conclusions that can be drawn, and all-encompassing recommendations.

Amongst the conclusions reached by the panel, the following are perhaps amongst the most critical. Firstly, there is a need for South Africa to assess the extent of technically recoverable shale gas resources and to commit to a balanced long-term gas exploitation strategy, taking account of the security of supply, efficiency of extraction, environmental protection and effective communication to society.

Secondly, it is essential that controls be identified and implemented regarding externality costs associated with mines and abandoned mines, and that these controls be in place even before the implementation phase begins. Third on the list is the need for a rigorous environmental impact assessment of both upstream and downstream shale gas processes and determination of the most economically, socially and environmentally optimal gas source. Fourthly, water availability and use, as well as the impact of methane emissions must be assessed and monitored another facet of environmental, social and health assessment.

The fifth conclusion drawn by the panel focuses, appropriately enough, on the potential impacts of mining on the astronomical work in progress and moving forward in Sutherland. Fracking and its supporting activities present a real risk to the scientific operations and performance of the Square Kilometre Array (SKA) and its complementary research utilities and functions. The extreme sensitivity of the SKA means that even the weakest of human-made radio signals is detectable at some level, and in some part of the radio frequency spectrum across which the SKA will operate. To minimise the potential impact of this risk, careful management and coordination with stakeholders is needed, along with the establishment of safety limits.

Sixth, comes the critical matter of the social and economic impacts of, and implications for, the mining. So far, much of the focus at a broad level has centred on the wider economic impacts and benefits to the national economy and energy balance, but completely inadequate consideration has been given to the localised effects of the impacts and consequences that will be faced and experienced in local environments. Then too, comes the seventh set of conclusions, critical if for no other reason than that they have been neglected in South Africa for over a hundred years: what happens when the mining operations come to a material or economic end? Ensuring complete maintenance throughout the operational life of wells, and after their closure, must form an essential part of any shale gas mining operation.

The report sets out three further conclusions relating to baseline studies prior to implementation; to the distribution of the gas; and to the importance of capacity and related skills development. These are clearly of equal importance.

These conclusions lay out essential steps that must be taken and actions that must be implemented if the fracking goes ahead. There is little doubt that the DST will take them seriously, as it is a department fortunate enough to have excellent leadership. It is very clear, however, that the Ministries of Mineral Resources and of Energy appear not to benefit from the same quality of leadership or commitment to good, honest practice.

Which brings us decisively back to the community activists. Should fracking proceed, to a greater or lesser degree, then the panel's conclusions (and recommendations) must be the essential, unchallenged foundations for the process. In this case, the activists still have an unquestionably critical (and possibly even more important) role to play: that of vociferously and persistently holding the state and its various arms to full account.

\section{References}

1. Vaughan A. Fracking given UK go-ahead as Lancashire council rejection overturned. The Guardian. 2016 October 06;Environment. Available from: https://www.theguardian.com/environment/2016/oct/06/uk-fracking-givengo-ahead-as-lancashire-council-rejection-is-overturned

2. Savides M. I'll make sure it doesn't happen - chief. Sunday Times. 2016 October 09;News. Available from: http://www.timeslive.co.za/sundaytimes/ stnews/2016/10/09/III-make-sure-fracking-doesnt-happen---chief

3. Academy of Science of South Africa (ASSAf). South Africa's technical readiness to support the shale gas industry. Pretoria: ASSAf; 2016. http:// dx.doi.org/10.17159/assaf.2016/0003 